\title{
Methylenetetrahydrofolate reductase genetic polymorphisms and toxicity to 5-FU-based chemoradiation in rectal cancer
}

\author{
F Thomas", 1,2, AA Motsinger-Reif ${ }^{1,3,4}$, JM Hoskins', A Dvorak', S Roy ${ }^{3}$, A Alyasiri ${ }^{5}$, RJ Myerson ${ }^{6}$, JW Fleshman ${ }^{7}$, \\ BR Tan ${ }^{5}$, HL McLeod ${ }^{1,5}$
}

'UNC Institute for Pharmacogenomics and Individualized Therapy, University of North Carolina, Chapel Hill, NC, USA; ${ }^{2}$ EA3035, Université de Toulouse, Institut Claudius Regaud, 20-24, rue du Pont St Pierre, Toulouse cedex 31 052, France; ${ }^{3}$ Department of Statistics, North Carolina State University, Raleigh, NC, USA; ${ }^{4}$ Bioinformatics Research Center, North Carolina State University, Raleigh, NC, USA; ${ }^{5}$ Department of Medicine, Washington University School of Medicine, St Louis, MO, USA; ${ }^{6}$ Department of Radiation Oncology, Washington University School of Medicine, St Louis, MO, USA; ${ }^{7}$ Department of Surgery, Washington University School of Medicine, St Louis, MO, USA

BACKGROUND: There is a large degree of variation in tumour response and host toxicities associated with neoadjuvant chemoradiation for rectal cancer patients. We performed a complimentary pharmacogenetic study to investigate germline polymorphisms of genes involved in 5-fluorouracil (5-FU) and irinotecan pathways and their potential association with clinical outcomes and toxicities from neoadjuvant chemoradiation in patients with rectal cancer treated in a prospective genotype-directed study.

METHODS: The germline DNA of I 3 I patients was genotyped for 10 variants in TYMS, MTHFR, DPYD, UGTIAI, ABCCI and SLCOIB I genes. Ninety-six patients were treated with 5-FU/radiotherapy (RT) and 35 received 5-FU/RT/irinotecan. Relationships between genetic variants and adverse events, tumour response, overall and disease-free survivals were assessed.

RESULTS: MTHFR 1298A >C and MTHFR diplotypes (for 677C > T and 1298A > C) were associated with chemoradiation-related toxicity when 5-FU was used alone. MTHFR haplotypes (677C-1298C) and diplotypes (CA-TA and TA-TA) showed, respectively, a protective and a negative effect on the incidence of severe diarrhoea or mucositis. No association was observed between genetic markers and drug response.

CONCLUSION: MTHFR polymorphisms can potentially predict toxicity in patients treated with 5-FU as a single chemotherapeutic drug. British Journal of Cancer (20II) I 05, 1654- 1662. doi:I0.1038/bjc.201 I.442 www.bjcancer.com

Published online I November 201 |

(c) 2011 Cancer Research UK

Keywords: MTHFR polymorphisms; 5-FU; mucositis; diarrhoea; rectal cancer; neoadjuvant chemoradiation

Neoadjuvant fluoropyrimidine-based chemoradiation is currently the standard therapy for patients with locally advanced rectal cancer (Sauer et al, 2004; Roh et al, 2009). Preoperative treatment was associated with lower risks of local recurrence and lower toxicities compared with radiotherapy (RT) alone (Bosset et al, 2006; Gerard et al, 2006; Braendengen et al, 2008) or postoperative chemoradiation CRT (Sauer et al, 2004; Roh et al, 2009). Pathologic downstaging (DS) or a pathologic complete response (pCR) after preoperative CRT has been correlated with improved survival, decreased recurrence and a higher rate of sphincterpreserving surgeries (Theodoropoulos et al, 2002; Valentini et al, 2002; Garcia-Aguilar et al, 2003; Crane et al, 2003b). The pCR and the DS rates observed with 5-fluorouracil (5-FU)-based CRT are $10-20 \%$ (Sauer et al, 2004; Bosset et al, 2005) and $~ 50-65 \%$ (Garcia-Aguilar et al, 2003; Crane et al, 2003a), respectively.

The efficacy of other drugs available in colon cancer treatment, including capecitabine (Dunst et al, 2002), oxaliplatin (Aschele et al, 2009; Gerard et al, 2010), irinotecan (Mohiuddin et al, 2006),

*Correspondence: Dr F Thomas;

E-mail: thomas.fabienne@claudiusregaud.fr

Received I4 July 2011; revised 21 September 2011; accepted 28

September 20 I I; published online I November 20 I I cetuximab (Bertolini et al, 2009) or bevacizumab (Willett et al, 2009), has been evaluated in this setting with various results in terms of tumour response but to date, no benefit on survival was observed compared with the current 5-FU regimen. In the context of multiple treatment possibilities, the identification of predictive markers of response to chemoradiotherapy treatment is a challenging approach for drug selection in order to obtain the best clinical benefit while minimising the side effects for each patient.

5-Fluorouracil is an antimetabolite of the pyrimidine analogue type that inhibits DNA and RNA synthesis (Figure 1). Its main mechanism of action consists of inhibition of thymidylate synthase (TS) through an active metabolite, fluorodeoxyuridine monophosphate (FdUMP), which forms an inactive ternary complex with TS and 5-10-methylenetetrahydrofolate (MTHF). Optimal inhibition of TS requires an elevated level of MTHF, which is regulated by the enzyme methylenetetrahydrofolate reductase (MTHFR). As a consequence, both TS and MTHFR activities are presumed to be major determinants of 5-FU clinical response. Genetic polymorphisms with functional impact on the activity and/or expression of both enzymes have been described.

A polymorphism within the promoter enhancer region (TSER) of TYMS (the TS gene), consisting of tandem repeats of $28 \mathrm{bp}$, has been implicated in modulating TS mRNA expression 


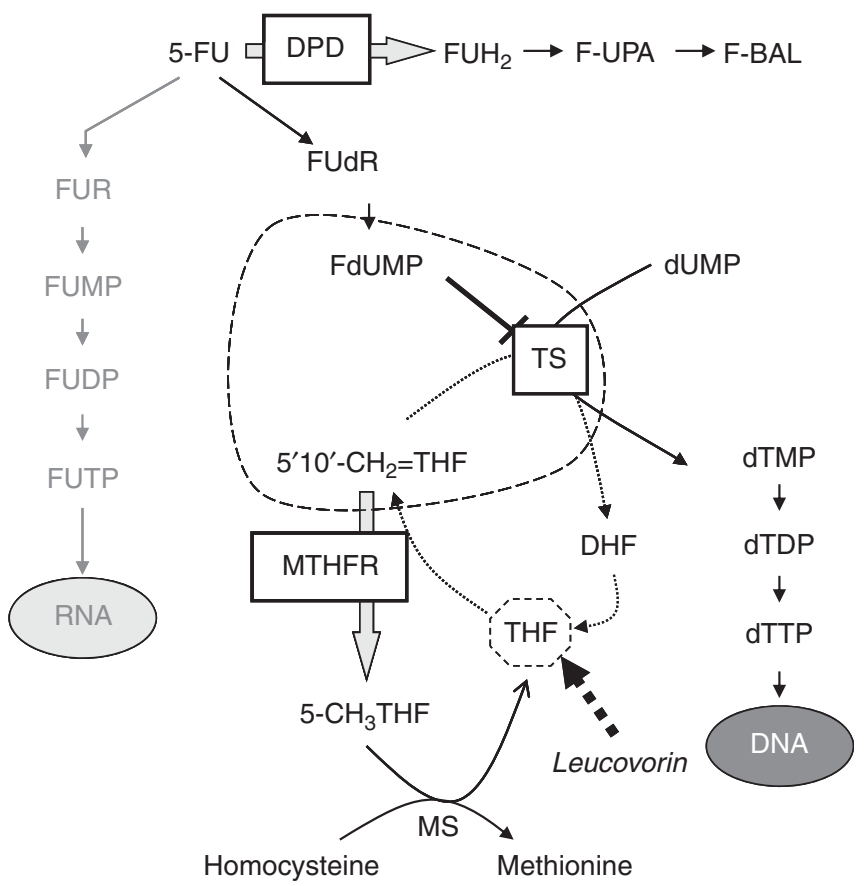

Figure I 5-Fluorouracil pathway. Abbreviations: DPD = dihydropyrimidine dehydrogenase; $\mathrm{FUH}_{2}=$ dihydrofluorouracil; $\mathrm{F}-\mathrm{UPA}=$ fluoro- $\beta$-ureidopropionate; $F-B A L=5$-fluoro- $\beta$-alanine; $F U R=$ fluorouridine; $F U M P=$ fluorouridine monophosphate; FUDP = fluorouridine diphosphate; $F U T P=$ fluorouridine $\quad$ triphosphate; $\quad F U d R=5$-fluorodeoxyuridine; $\mathrm{dUMP}=$ deoxyuridine $\quad 5^{\prime}$-monophosphate; $\quad \mathrm{dTMP}=$ deoxythymidine 5'-monophosphate; dTDP = deoxythymidine 5'-diphosphate; dTTP= deoxythymidine 5'-triphosphate; $5-10-\mathrm{CH}_{2} \mathrm{THF}=5-10$-methylenetetrahydrofolate; $5-\mathrm{CH}_{3} \mathrm{THF}=5$-methyltetrahydrofolate; $\mathrm{THF}=$ tetrahydrofolate; $\mathrm{DHF}=$ dihydrofolate; $\mathrm{MTHFR}=$ methylenetetrahydrolate reductase: $M S=$ methionine synthetase

(Kaneda et al, 1987; Horie et al, 1995) and TS mRNA translational efficiency (Kawakami et al, 2001). The most common alleles are the double repeat $\left(2 \mathrm{R}, \mathrm{TSER}^{\star} 2\right)$ and triple repeat $\left(3 \mathrm{R}, \mathrm{TSER}^{\star} 3\right)$. In vitro and in vivo studies have shown that increasing the number of repeats (from $2 \mathrm{R}$ to $3 \mathrm{R}$ ) leads to a stepwise increase in TS expression (Horie et al, 1995; Kawakami et al, 1999; Pullarkat et al, 2001).

TSER $* 3$ homozygosity appears to be associated with a lower response to neoadjuvant 5-FU-based CRT for patients with rectal cancer (Villafranca et al, 2001; Spindler et al, 2007). Thus, we conducted a prospective non-randomised single-institution phase II study using TYMS genotyping to direct neoadjuvant CRT for patients with locally advanced and metastatic rectal cancer. Patients with germline TSER $* 2 / 2$ or TSER $* 2 * 3$, deemed 'good risk' for a favourable response to 5-FU, were treated with standard CRT. Poor-risk patients with a TSER $* 3 / * 3$ or TSER $* 3 / * 4$ genotypes who were unlikely to derive significant benefit from 5-FU chemotherapy, were treated with irinotecan in addition to standard 5-FU/CRT. The clinical results of this study have been published (Tan et al, 2011) and showed that patients of the poorrisk group can achieve similar tumour DS and pCR rates to patients of the good-risk group when irinotecan was added to the 5-FU/RT regimen. However, in each genotype/treatment group, there was inter-individual variability in tumour response and treatment toxicities. Several studies regarding pharmacogenetic predictors of 5-FU pharmacodynamics have been conducted in colorectal cancer patients with inconsistent results (Etienne et al, 2004; Ruzzo et al, 2007, 2008; Capitain et al, 2008; Gusella et al, 2009). We performed a complimentary retrospective pharmacogenetic study investigating germline polymorphisms of genes involved in 5-FU and irinotecan pathways to assess their putative role in the prediction of outcome or toxicity in rectal cancer patients receiving 5-FU-based chemoradiation.

\section{MATERIALS AND METHODS}

\section{Patients and treatment}

All patients were included in a clinical phase II study using TYMS genotyping to direct neoadjuvant CRT for patients with rectal cancer (Tan et al, 2011). Patients were eligible to participate in the study if they were 18 years old or older, with biopsy-proven clinical T3/T4, N0-2, M0-1 adenocarcinoma of the rectum and a Karnofsky performance status of $\geqslant 60 \%$. Patients with metastatic disease, whose primary tumours were deemed resectable, were also eligible. Patients who qualified had adequate haematologic (absolute neutrophil count $1500 \mathrm{~mm}^{-3}$, platelets count $\geqslant 100000 \mathrm{~mm}^{-3}$ ), renal (creatinine $\leqslant 2.0 \mathrm{mg} \mathrm{dl}^{-1}$ ) and hepatic functions with total bilirubin $\leqslant 2.0 \mathrm{mg} \mathrm{dl}^{-1}$, SGOT and alkaline phosphatase $\leqslant 2 \times$ upper limit of normal. Exclusion criteria included prior pelvic radiation, prior malignancies in the past 5 years except for skin cancer and in situ cervical cancers and known allergy to 5-FU or irinotecan. This study was approved by the Institutional Review Board at Washington University School of Medicine and informed consent was obtained from all participants before enrolment.

Before treatment, clinical staging was performed, blood samples were obtained and TSER polymorphisms were evaluated using a previously described PCR-based assay (Marsh et al, 1999). Patients carrying at least one ${ }^{*} 2$ allele $\left(\operatorname{TSER}^{\star} 2 /^{\star} 2,{ }^{\star} 2{ }^{*} 3\right.$, or ${ }^{*} 2{ }^{*} 4$ ) were assigned to the good-risk genotype group (i.e. group 1) and treated with standard preoperative CRT. Radiotherapy consisted of a total of 45-50.4 Gy delivered in 25-28 fractions (180-200 cGy per fraction) by a multiple field technique using image-guided radiotherapy with radiotherapy target volume consistent with the Radiation Therapy Oncology Group consensus guidelines (Myerson et al, 2009). Concurrent continuous intravenous infusion of $5-\mathrm{FU}$ at a dose of $225 \mathrm{mg} \mathrm{m}^{-2}$ per day was administered throughout radiation without leucovorin. Patients with TSER $* 3 / * 3$ or TSER ${ }^{\star} 3{ }^{*} 4$ genotypes were assigned to the poor-risk genotype group (i.e. group 2 ) and treated with weekly intravenous irinotecan at $50 \mathrm{mg} \mathrm{m}^{-2}$ for 5 weeks in addition to standard CRT identical to the treatment in the good-risk group. Clinical restaging and resection of the primary rectal lesion were performed 6-10 weeks after completion of preoperative CRT.

\section{Evaluation of patients}

Baseline clinical tumour staging, using rigid proctoscopy, transrectal ultrasound (TRUS), spiral computed tomography (CT) or magnetic resonance imaging (MRI), were performed within 28 days of enrolment. Clinical restaging with TRUS, CT or MRI was repeated before resection. The surgical procedure performed was at the discretion of the treating surgical oncologist. Standardised institutional pathology examinations were done, and the pathologic staging as well as the extent of residual tumour in the resected specimen were classified using the American Joint Committee on Cancer version 6. Tumour DS was defined as a decrease in the T stage of the primary tumour by at least 1 . Tumour complete response (ypT0) was defined as the absence of any viable tumour in the rectum. Toxicities were graded according to the National Cancer Institute Common Toxicity Criteria (NCI-CTC) version 2.0. Recurrence and survival were also monitored.

\section{Genotype analysis}

Genomic DNA was isolated from whole blood using the Puregene DNA isolation kit (Qiagen, Hilden, Germany). 
Based on previous published studies, the 5-FU-related genetic polymorphisms selected for testing were TYMS TSER 3 G $>$ C (rs2853542), two intronic SNPs c.205+117G $>$ C (rs2853533) and c.280-499G $>$ A (rs2847153), MTHFR 677C $>$ T (rs1801133, currently referred as c.665C $>\mathrm{T}$ ) and 1298A $>\mathrm{C}$ (rs1801131, currently referred as c.1286A $>C$ ) and $D P Y D^{\star} 2 \mathrm{~A}(\mathrm{rs} 3918290)$.

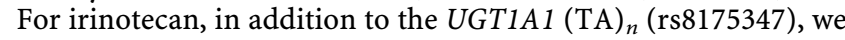
genotyped samples for the UGT1A1 -3156G > A SNP (rs10929302, currently referred as c.862-9898G $>\mathrm{A}$ ), and two polymorphisms in transporters, $A B C C 1$ c. $1474-48 \mathrm{C}>\mathrm{T}$ (rs3765129) and SLCO1B1 c.388A $>\mathrm{G}$ ( $\mathrm{rs} 2306283)$ that have been described to have an effect on irinotecan toxicity (Innocenti et al, 2009).

For TYMS TSER $* 3$ G $>$ C SNP, the PCR and the RFLP were performed as described previously (Thomas et al, 2010). The TYMS TSER $* 3 \mathrm{G}>\mathrm{C}$ SNP leads to a change of a critical residue in the upstream stimulatory factor E-box consensus element (CACTTG $>$ CACTTC). The number of theoretical E-box-binding sites likely to bind USF proteins was deduced based on the TYMS $\mathrm{G}>\mathrm{C}$ genotype: one E-box for genotypes $2 \mathrm{RC} / 3 \mathrm{RC}$ or $2 \mathrm{RC} / 2 \mathrm{RG}$, two E-boxes for genotypes $2 \mathrm{RG} / 2 \mathrm{RG}$ or $2 \mathrm{RG} / 3 \mathrm{RC}$ or $3 \mathrm{RC} / 3 \mathrm{RC}$ or $2 R C / 3 R G$, three E-boxes for $2 R G / 3 R G$ or $3 R C / 3 R G$, four E-boxes for $3 R G / 3 R G$ or $2 R G / 4 R$ or $3 R C / 4 R$ and five E-boxes for $3 R G / 4 R$. TYMS genotypes with $\leqslant 2$ E-boxes were classified as 'low expression of TS' and $\geqslant 3$ were classified as 'high expression of TS' as proposed by Kawakami and Watanabe (2003).

Genotypes for TYMS c. $205+117 \mathrm{G}>\mathrm{C}$, TYMS c.280-499G $>\mathrm{A}$ and $S L C O 1 B 1^{*} 1 \mathrm{~b} 388 \mathrm{~A}>\mathrm{G}$ were determined using allelic discrimination with TaqMan SNP Genotyping assays (Applied Biosystems, Foster City, CA, USA) C_26612339_10 and C_1637481_10 and C_1901697_20, respectively.

Genotyping for MTHFR $6 \overline{6} 7 \mathrm{C}>\mathrm{T}$, MTHFR $1298 \mathrm{~A}>\mathrm{C}, D P Y-$ $D * 2 \mathrm{~A}, U G T 1 A 1(\mathrm{TA})_{n}$ and UGT1A1 $-3156 \mathrm{G}>\mathrm{A}$ were determined using pyrosequencing as previously described (Marsh et al, 2005; McLeod et al, 2010). ABCC1 IVS11 -48C $>\mathrm{T}$ was genotyped using pyrosequencing (Marsh et al, 2005) with the following primers: biotinylated-forward $5^{\prime}$-AGCATGGTGAAACCCATCT-3'; reverse $5^{\prime}$-TCAGCTTGATCCGATTGTCTT- $3^{\prime}$ and sequencing $5^{\prime}$-G GGCGACCCTGGGAT-3'.

\section{Statistics}

Each SNP was tested for deviation from Hardy-Weinberg equilibrium. Since not all SNPs are biallelic, binomial expansions of the equation were used to compute expected values. $\chi^{2}$ tests of association were used if the expected value of each cell was $>5$, and Fisher's exact tests were used when the cells were too sparse. Additionally, tests for deviation from Hardy-Weinberg proportions were performed two ways: first on the entire cohort $(n=131)$ and second on Caucasian samples only $(n=111$, other racial groups did not have enough individuals for stratified analysis).

Relationships between genetic variants and the incidence of grade 3-4 toxicity, tumour response (measured by DS and ypT0 rates), overall and disease-free survivals were assessed.

The association analyses were performed for each genotype variable, using categorical genotypic encodings. For each genotype variable and outcome combination, traditional tests of hypotheses were performed based on the data types in the model, and whether the data met parametric assumptions. When possible, parametric tests were performed to increase power, and non-parametric tests were used when statistical assumptions were not met. Contingency table analyses and proportional hazards analyses were used for the categorical outcomes and time-to-event outcomes, respectively. When significant associations were found, corresponding odds ratios (ORs) and their 95\% confidence intervals (95\% CIs) were calculated. Permutation tests were performed to correct for multiple testing for each outcome leading to different cutoff $P$-values for each outcome. Additionally, multiple logistic regression analysis was performed for each of the four outcomes against the different treatments using both markers and treatment as factor. The model was logit $(y)=$ intercept + marker + treatment + marker $\times$ treatment. If no significant results were seen in the multiple regression analyses, details are not shown. Analysis was performed in Stata v.11 (StataCorp LP, College Station, TX, USA; http://www.stata.org) and R (http://www.r-project.org and http://cran.r-project.org/doc/FAQ/R-FAQ.html). Haplotypes were determined with Shape-IT, publicly available at http://www.griv. org/shapeit/ (Delaneau et al, 2008).

\section{RESULTS}

\section{Patients and treatment outcome}

There were 131 patients treated and evaluable for assessment of toxicity, overall survival (OS) and recurrence-free survival (RFS) (both considered as intent to treat). Among the 131 patients, 96 were assigned to group 1 based on their TYMS TSER genotype and were treated with 5-FU + RT and 35 were in the group 2 and were treated with $5-\mathrm{FU}+\mathrm{RT}+$ irinotecan. As shown in Table 1, a total of 10 patients were inevaluable for tumour DS and ypT0 evaluation, mostly for surgery issues. The clinical results have been previously published (Tan et al, 2011) and are summarised in Table 1. Briefly, in group 1, the DS and ypT0 rates were $64.4 \%$ and $20 \%$, respectively. Grade 3 or 4 toxicities occurred in $30.2 \%$ of patients.

In group 2, which was treated with 5-FU + RT + irinotecan, 19 of the $35(54.3 \%)$ patients experienced grade 3-4 toxicities and the DS and ypT0 rates were $64.5 \%$ and $41.9 \%$, respectively. To assess the impact of the genotype on treatment-specific toxicity, the existence of grade 3/4 diarrhoea and/or mucositis has been considered together for patients treated with 5-FU + RT (Table 1).

\section{Genotyping}

The genotyping results are presented in Table 2. For the TYMS TSER ${ }^{\star 3} \mathrm{G}>\mathrm{C}$ SNP, five alleles were identified: 2RC, $2 R G, 3 R C$, $3 R G$ and $4 \mathrm{R}$. Among the patients carrying the $3 \mathrm{RC}$ allele, two displayed an unexpected size of the $3 R$ allele that was due to a 6-bp insertion (CCCCCG) in the second repeat of the $3 \mathrm{R}$ allele. This particular finding has been recently reported (Thomas et al, 2010). For the current pharmacogenetic study, these two patients have been considered as carrying the 3RC allele because their small number did not allow studying them separately. Genotypes were

Table I Treatment outcomes used as variables in the pharmacogenetic study

\begin{tabular}{lcc}
\hline & $\begin{array}{c}\text { Group I } \\
\text { (5-FU+ } \\
\text { radiotherapy- } \\
\text { treated group) }\end{array}$ & $\begin{array}{c}\text { Group 2 (5-FU+ } \\
\text { radiotherapy+ } \\
\text { irinotecan- } \\
\text { treated group) }\end{array}$ \\
\hline Total number of patients & 96 & 35 \\
Number of evaluable patients for & & \\
DS and ypT0 & 90 & 31 \\
Overall and relapse-free survivals & 96 & 35 \\
Toxicity & 96 & 35 \\
Tumour DS & $58(64.4 \%)$ & $20(64.5 \%)$ \\
ypT0 & $18(20 \%)$ & $13(41.9 \%)$ \\
3-year overall survival & $78.2 \%$ & $83.6 \%$ \\
3-year relapse-free survival & $70.7 \%$ & $68.4 \%$ \\
Grade 3-4 toxicity & $29(30.2 \%)$ & $19(54.3 \%)$ \\
Grade 3-4 diarrhoea & $16(45.7 \%)$ \\
and/or mucositis & $21(21.9 \%)$ & \\
\hline
\end{tabular}

Abbreviations: DS= downstaging; ypT0 = tumour complete response; 5-FU= 5-fluorouracil. 
Table 2 Genotype and allele frequencies for the genetic polymorphisms tested

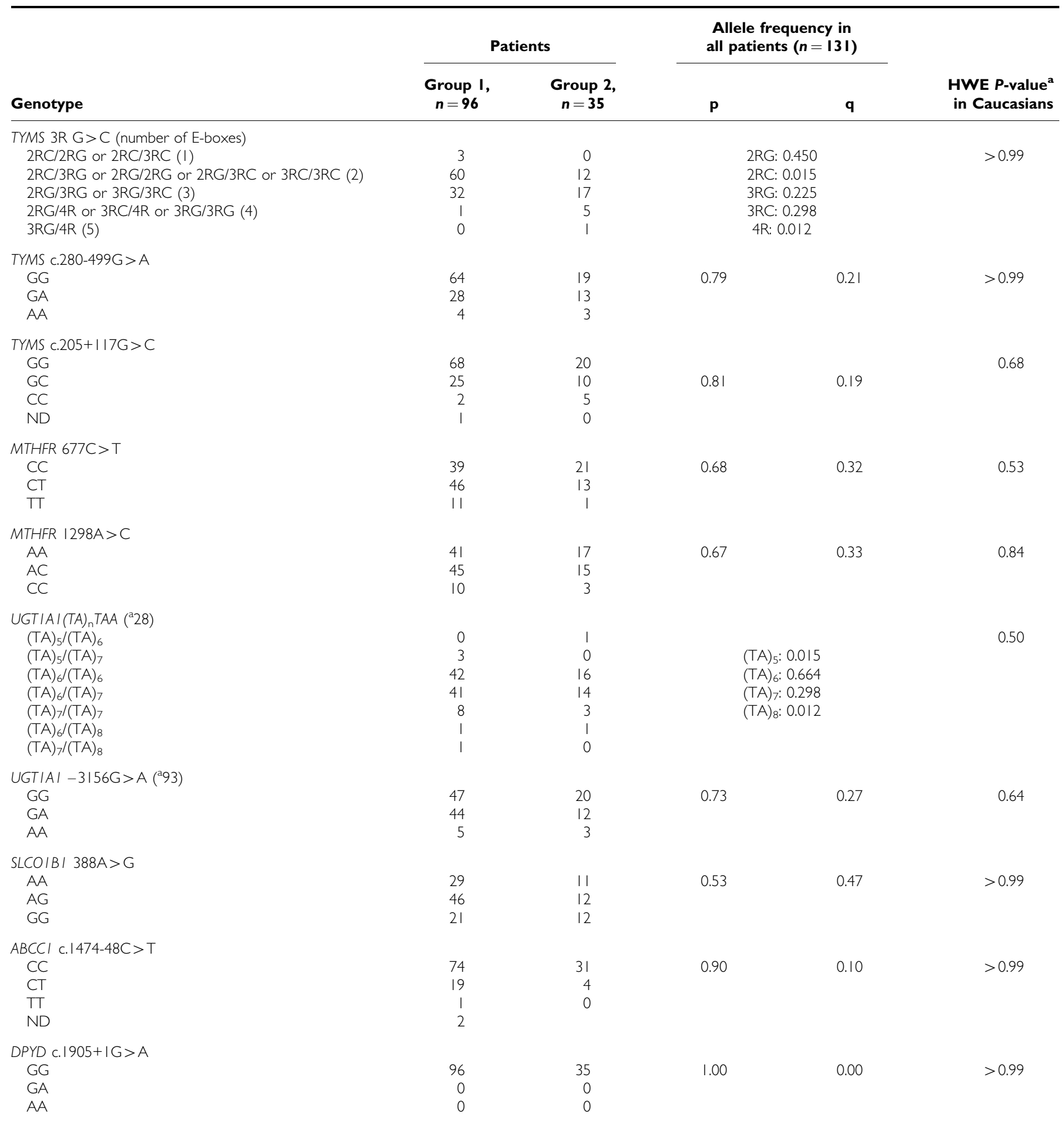

Abbreviations: HWE = Hardy-Weinberg equilibrium; MTHFR = methylenetetrahydrofolate reductase. ${ }^{\mathrm{a} C a l c u l a t e d}$ with Fisher's exact test, except for TYMS $3 R$ G $>C$ and UGTIAI(TA) TAA that were calculated with $\chi^{2}$ test. The P-values reported are uncorrected for multiple comparisons.

first grouped based on the number of E-boxes (as shown in Table 2) and then into 'low expression' vs 'high expression' of TS for statistical analyses. It is noteworthy that the repartition of these genotypes is biased in each group since the groups have been created based on the TYMS TSER polymorphism $\left({ }^{*} 2 /{ }^{\star} 2+{ }^{*} 2\right.$ / $\left.{ }^{*} 3+{ }^{*} 2 /{ }^{*} 4 v s^{*} 3 /{ }^{*} 3+{ }^{*} 3 / * 4\right)$. No $D P Y D^{\star} 2 A$ variant was identified in the studied cohort of patients. The observed genotypes were in agreement with the Hardy-Weinberg equilibrium in the
Caucasian population. The resulting $P$-values from these tests are shown in Table 2 for the 111 Caucasians out of the 131 patients.

Haplotypes for MTHFR $677 \mathrm{C}>\mathrm{T}$ and $1298 \mathrm{~A}>\mathrm{C}$ were also analysed. Four haplotype identities were observed; although the TC haplotype had a very low frequency $(0.38 \%)$ compared with CA $(35.9 \%)$, CC $(32.4 \%)$ and TA $(31.3 \%)$ haplotypes. Linkage disequilibrium was weak between these two SNPs with $r^{2}=0.27$ in Caucasians, which is similar to that reported in the HapMap 
Table 3 Associations between MTHFR genotypes, haplotypes and diplotypes and grade 3-4 diarrhoea and/or mucositis

\begin{tabular}{|c|c|c|c|c|c|c|}
\hline & \multicolumn{3}{|c|}{ Group I } & \multicolumn{3}{|c|}{ Group 2} \\
\hline & $\begin{array}{l}\text { Number of patients (\%) } \\
\text { without G3-4 diarrhoea } \\
\text { and/or mucositis, } \\
N=75(78 \%)\end{array}$ & $\begin{array}{l}\text { Number of patients (\%) } \\
\text { with G3-4 diarrhoea } \\
\text { and/or mucositis, } \\
N=21(22 \%)\end{array}$ & $P$-value ${ }^{a}$ & $\begin{array}{c}\text { Number of patients (\%) } \\
\text { without G3-4 diarrhoea } \\
\text { and/or mucositis, } \\
N=19(54 \%)\end{array}$ & $\begin{array}{c}\text { Number of patients (\%) } \\
\text { with G3 -4 diarrhoea } \\
\text { and/or mucositis, } \\
N=16(46 \%)\end{array}$ & $P$-value ${ }^{a}$ \\
\hline \multicolumn{7}{|l|}{ MTHFR 677C > T } \\
\hline CC & $34(87)$ & $5(13)$ & & $12(57)$ & $9(43)$ & \\
\hline \multicolumn{7}{|l|}{ MTHFR $1298 \mathrm{~A}>C$} \\
\hline AA & $26(63)$ & $15(37)$ & & $9(53)$ & $8(47)$ & \\
\hline$A C$ & $4 \mid(9 \mid)$ & $4(9)$ & 0.005 & $9(60)$ & $6(40)$ & 0.699 \\
\hline $\mathrm{CC}$ & $8(80)$ & $2(20)$ & & I (33) & $2(67)$ & \\
\hline \multicolumn{7}{|l|}{ MTHFR haplotype } \\
\hline $677 C-1298 A$ & $33(73)$ & $12(27)$ & 0.329 & $15(58)$ & II (42) & 0.700 \\
\hline$C A-C C$ & $14(93)$ & I (7) & & $7(70)$ & $3(30)$ & \\
\hline CA-TA & $6(40)$ & $9(60)$ & & $4(50)$ & $4(50)$ & \\
\hline $\mathrm{CC}-\mathrm{CC}$ & 7 (78) & $2(22)$ & & I (33) & $2(66)$ & \\
\hline CC-TA & $27(90)$ & $3(10)$ & & $2(40)$ & $3(60)$ & \\
\hline $\mathrm{CC}-\mathrm{TC}$ & I (100) & $0(0)$ & & 0 & 0 & \\
\hline $\mathrm{TA}-\mathrm{TA}$ & $7(64)$ & $4(36)$ & & I $(100)$ & $0(0)$ & \\
\hline
\end{tabular}

Abbreviation: MTHFR = methylenetetrahydrofolate reductase. ${ }^{\mathrm{a}}$ Based on the permutation test, the $P$-value cutoff for significance was 0.009 . The significant $P$-values are shown in bold cases. The $P$-values reported are uncorrected for multiple comparisons.

Caucasian population $\left(r^{2}=0.22\right)$, and $r^{2}=0.20$ in all patients (http://hapmap.ncbi.nlm.nih.gov/).

\section{Genetic polymorphisms and drug response to 5 -FU}

Drug response was assessed with four variables: tumour DS, ypT0, OS and RFS. The following genetic markers were tested for associations with drug response: TYMS $3 \mathrm{R} \mathrm{G}>\mathrm{C} \mathrm{SNP}$, the number of TYMS E-boxes, TS expression, the two intronic TYMS SNPs (rs2847153 and rs2853533), MTHFR $677 \mathrm{C}>\mathrm{T}$, and $1298 \mathrm{~A}>\mathrm{C}$, MTHFR diplotype for $677 \mathrm{C}>\mathrm{T}$ and $1298 \mathrm{~A}>\mathrm{C}$ and $M T H F R$ haplotypes. The analyses were first performed in the group 1 to assess the impact of genetic markers on response to 5-FU alone. All markers except those regarding the TSER region of TYMS (TYMS $3 \mathrm{R}$ G $>$ C SNP, the number of TYMS E-boxes and the TS expression) were also tested in the whole group $(n=131)$ representing a mix of patients treated with 5-FU alone or in combination with irinotecan. None of the genotypes was significantly associated with drug response in group 1 or the whole group.

\section{Genetic polymorphisms and 5-FU toxicity}

The same genetic markers were tested for associations with 5-FU toxicity in group 1. By considering the general grade 3-4 toxicity, one MTHFR diplotype (CA-TA) was significantly related to a higher rate of grade 3-4 toxic events $(P=0.006)$. The MTHFR genotypes, haplotypes and diplotypes were then analysed with regards to 5-FU-specific toxicity such as diarrhoea and mucositis. The results are presented in Table 3 and Figure 2. The MTHFR 1298 A > C genotype was significantly associated with grade 3-4 diarrhoea and/or mucositis $(P=0.005)$, with patients with the A/A genotype having a higher risk of toxicity $(\mathrm{OR}=4.71 ; 95 \%$ $\mathrm{CI}=1.63$, 13.59) compared to patients with the $\mathrm{A} / \mathrm{C}$ or $\mathrm{C} / \mathrm{C}$ genotype (Figure 2A). Although not significant, the $677 \mathrm{C} / \mathrm{C}$ genotype tended to be protective from G3-4 diarrhoea and/or mucositis, as shown in Figure 2B. Consistent with these results, the
MTHFR CC (677C-1298C) haplotype was associated with a lower incidence of G3-4 diarrhoea and/or mucositis (Figure 2D; $P=0.005 ; \mathrm{OR}=0.21 ; 95 \% \mathrm{CI}=0.074,0.61)$. The MTHFR diplotype showed that the patients carrying the CA-TA and TA-TA diplotypes had a higher risk $(\mathrm{OR}=7.75 ; 95 \% \mathrm{CI}=2.67,22.47)$ of developing grade 3-4 diarrhoea and/or mucositis $(P=0.003$; see Figure 2C). These relationships between MTHFR markers and grade 3-4 diarrhoea and/or mucositis were not observed in group 2 , which was treated with $5-\mathrm{FU}+\mathrm{RT}+$ irinotecan.

\section{Genetic polymorphisms and drug response to 5-FU + irinotecan}

Associations between UGT1A1 (TA) ${ }_{n}$ UGT1A1 -3156G $>$ A, $S L C O 1 B 1^{*} 1 b \quad 388 \mathrm{~A}>\mathrm{G}$ and $A B C C 1$ IVS1 $1-48 \mathrm{C}>\mathrm{T}$ genotypes and drug response (tumour DS, ypT0, OS and RFS) to 5-FU + irinotecan were evaluated for the 35 patients of group 2 . None of these markers was significantly associated with drug response.

\section{Genetic polymorphisms and 5-FU + irinotecan toxicity}

The impact of UGT1A1 (TA) ${ }_{n}$ UGT1A1 $-3156 \mathrm{G}>\mathrm{A}, S L C O 1 B 1^{\star} 1 \mathrm{~b}$ $388 \mathrm{~A}>\mathrm{G}$ and $A B C C 1$ IVS11 $-48 \mathrm{C}>\mathrm{T}$ genotypes was evaluated on toxicity related to 5 -FU + irinotecan, for example, in the 35 patients of group 2 . None of these markers was associated with grade 3-4 overall toxicity.

\section{DISCUSSION}

The main finding of this study is that MTHFR polymorphisms are associated with 5-FU-specific toxicity when 5-FU is used alone. Patients carrying the 1298A/A genotype have a higher risk of developing grade 3-4 diarrhoea or mucositis compared to patients with the A/C or $\mathrm{C} / \mathrm{C}$ genotype when treated with 5 -FU alone but this risk was not observed in patients treated with 5-FU and 

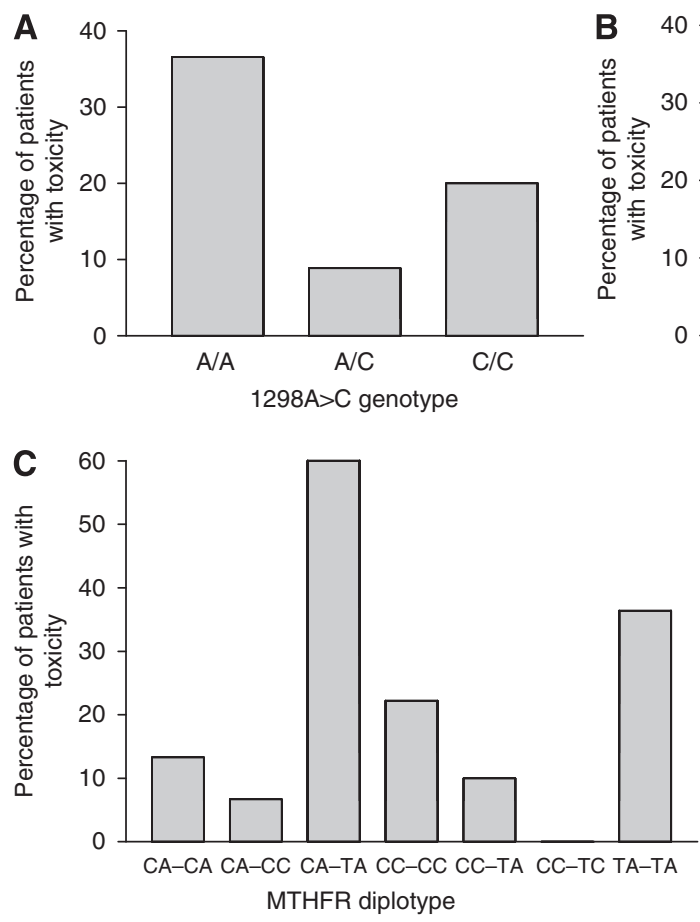
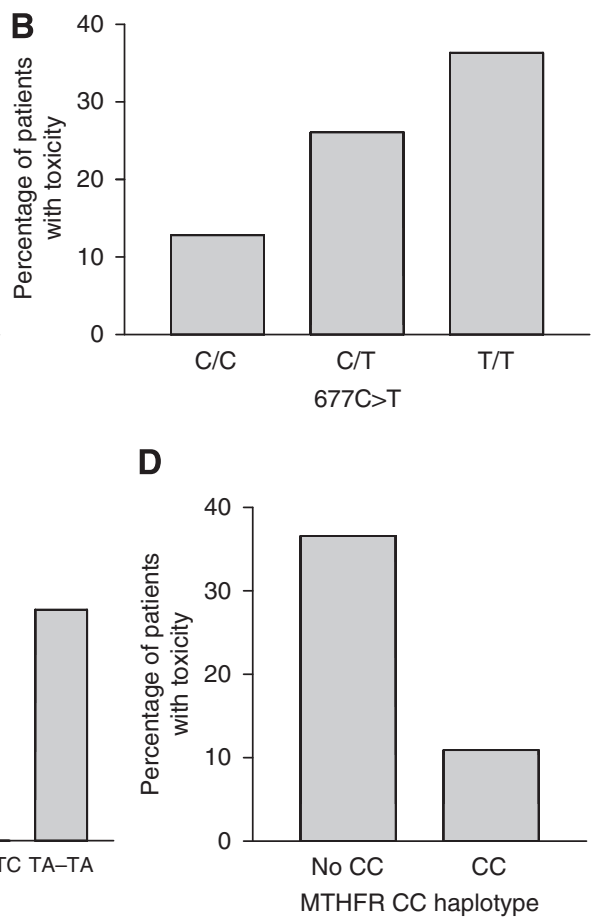

MTHFR CC haplotype

Figure 2 Relationships between incidence of grade 3-4 diarrhoea and/or mucositis experienced by patients treated with 5-FU/RT (group I) with MTHFR 1298A > C genotype (A), MTHFR 677C > T genotype (B), MTHFR diplotype (C) and MTHFR CC haplotype (D).

irinotecan. By considering the MTHFR haplotypes, we observed that only $10 \%$ of the patients carrying the $677 \mathrm{C}-1298 \mathrm{C}$ haplotype experienced grade 3-4 diarrhoea or mucositis compared with $36 \%$ of patients with other haplotypes, suggesting that the CC haplotype confers a protective effect. Consistent with these observations, two MTHFR diplotypes CA-TA and TA-TA (homozygous wild type for $1298 \mathrm{~A}>\mathrm{C}$ and at least one variant allele for $677 \mathrm{C}>\mathrm{T}$ ) were predictive of a higher rate of grade 3-4 diarrhoea or mucositis. Opposite findings have been published by Capitain et al (2008), regarding the role of MTHFR $1298 \mathrm{~A}>\mathrm{C}$ polymorphism on 5-FU toxicity in colorectal patients. They found that homozygosity for MTHFR 1298C/C confers a higher risk of grade 3-4 toxic events. However, the effect of this polymorphism was not assessed on toxicity such as diarrhoea or mucositis and the percentage of patients undergoing serious toxic events was lower than in the present study. Moreover, the regimen used in their study included leucovorin whereas the patients in our study did not receive leucovorin in combination with 5-FU. This raises the question of the results inconsistency regarding the role of MTHFR polymorphisms as predictive markers of treatment outcome and toxicity that has been published in colorectal patients (De Mattia and Toffoli, 2009). It is hypothesised that MTHFR polymorphisms may augment the cytotoxic activity of 5 -FU by increasing intracellular concentrations of 5,10-methylentetrahydrofolate and then enhancing the formation and stability of the ternary inhibitory complex (Bagley and Selhub, 1998; Weisberg et al, 1998). MTHFR 1298C and 677T variants are then theoretically associated with a higher cytotoxicity. The trend we observed for $677 \mathrm{~T}$ being associated with a higher incidence of grade 3-4 diarrhoea or mucositis is in agreement with this hypothesis; on the contrary, the association observed between MTHFR 1298A variant and toxicity is opposite to what was expected. However, most of the studies investigating the role of MTHFR polymorphisms in colorectal patients treated with fluoropyrimidine-based chemotherapy have yielded conflicting results (reviewed in De Mattia and Toffoli, 2009). Among the reasons for these inconsistencies, we can mention the variety of drugs (oxaliplatin, irinotecan, etc.) co-administered with the fluoropyrimidine, different clinical settings (adjuvant, neoadjuvant, first- and second-line palliative chemotherapy), the route of administration for 5-FU (bolus and infusion) and finally the addition of leucovorin. All these factors might influence the associations between MTHFR polymorphisms and fluoropyrimidine activity.

Our study represents an ideal situation for investigating the role of MTHFR polymorphisms in 5-FU outcome because (i) 5-FU was given as monotherapy in group 1; (ii) no leucovorin was added to the 5-FU regimen; therefore, the pool of methylenetetrahydrofolate was directly controlled by MTHFR (see Figure 1); (iii) 5-FU cytoxicity, when given as a continuous infusion, has been shown to rely more on inhibition of TS activity and DNA synthesis than RNA inhibition (Tsujinaka et al, 1992; Noordhuis et al, 2004); and (iv) patients were chemonaive, which excludes the possibility of acquired resistance to chemotherapy. For patients treated with chemoradiation using irinotecan and 5-FU, the association of MTHFR genotype and toxicity could not be clearly defined. This can be due to the very small sample size $(n=35)$ but we can hypothesise that the effect of MTHFR polymorphisms on 5-FU toxicity is abrogated when irinotecan is added to the regimen. Indeed, the leading cause of diarrhoea observed in group 2 is certainly irinotecan and, therefore, seems independent on MTHFR. More so, the incidence of grade 3-4 diarrhoea was high $(45.7 \%)$ among patients treated with irinotecan-based chemoradiation, compared with $17.7 \%$ among those treated with 5-FU alone in our prospective study (Tan et al, 2011). This difference in toxicity between the two treatment groups may abrogate the effect MTHFR on toxicity among irinotecan-treated patients. Moreover, due to the trial design, groups 1 and 2 differ also from each other in terms of TYMS genotype. Therefore, we cannot exclude that the difference observed between the two groups for MTHFR effect may be due to TYMS genotype and not to different therapies.

This is the first study investigating the role of pharmacogenetics in 5-FU toxicity in rectal cancer while two studies have already looked at the influence of these genetic markers on drug response (Terrazzino et al, 2006; Balboa et al, 2010). Terrazzino et al (2006) 
showed that patients with the MTHFR 667T-1298A haplotype had a lower tumour regression rate compared with other haplotypes. However, among the 125 patients investigated, 25\% received 5-FU as a bolus and only $36 \%$ were treated with 5 -FU alone. More recently, Balboa et al (2010) found no relationship between MTHFR polymorphisms and tumour response, which is in agreement with our findings. The impact of MTHFR polymorphisms has also been evaluated on capecitabine toxicity in breast cancer patients (Largillier et al, 2006) and colorectal patients (Sharma et al, 2008). Although the first study did not identify any associations between MTHFR polymorphisms and toxicity, Sharma et al (2008) showed that the MTHFR 677T/T and 1298A/A genotypes were associated with a lower incidence of grade 2-3 overall toxicity, which is not in agreement with our findings. They also identified MTHFR diplotypes (CA-CC and CC-TA) that conferred a higher risk of toxicity. In our analysis, these diplotypes were not predictive of a higher incidence of toxicity. Among potential explanations for these discrepancies, we can mention that capecitabine, despite being an oral prodrug of 5-FU, presents some differences with 5-FU in the safety profile (e.g. lower incidence of stomatitis and diarrhoea, higher incidence of hand foot syndrome) (Cassidy et al, 2002). Also, in our study, we tested genotype associations with grade 3-4 toxicity whereas Sharma et al (2008) considered grade 2-3 toxic events because of low incidence of toxicity from capecitabine.

TYMS polymorphisms were not identified as predictive markers of drug response and toxicity in our study but it may be due to its design. Indeed, group 1 (treated with $5-\mathrm{FU}+\mathrm{RT}$ ) was only composed of patients with $\mathrm{TSER}^{\star} 2 /{ }^{\star} 2$ or TSER ${ }^{\star} 2{ }^{\star} 3$ genotypes, which decreased the incidence of the TSER ${ }^{\star} 3 \mathrm{G}>\mathrm{C}$ SNP in this group and then probably the range of TS activity. On the other hand, patients carrying the TSER $* 3 / * 3$ genotype and thereby being more susceptible to carry the TSER $* 3 \mathrm{G}>\mathrm{C}$ SNP were included in group 2 and treated with $5-\mathrm{FU}+\mathrm{RT}+$ irinotecan. The addition of irinotecan increased the incidence of grade $3-4$ adverse events and in particular diarrhoea. Thus, the addition of irinotecan to the regimen is a confounding factor and complicates the identification of relationships between the TYMS TSER ${ }^{\star 3} \mathrm{G}>\mathrm{C}$ SNP and 5-FU response or toxicity. For this reason, it is not possible to draw any conclusion regarding the lack of significant relationships between TYMS polymorphisms and 5-FU outcome from our study.

Regarding the pharmacogenetics of irinotecan, none of the genetic markers investigated was significantly associated with irinotecan toxicity and response. The low dose of irinotecan used in this regimen (i.e. $50 \mathrm{mg} \mathrm{m}^{-2}$ ) and the small number of patients treated $(n=35)$ might explain the lack of associations observed (Hoskins et al, 2007). Indeed, homozygosity for UGT1A1*28 has been clearly identified as a risk factor for developing severe irinotecan-induced neutropenia, while heterozygous patients seem at intermediate risk (Kim and Innocenti, 2007). Innocenti et al (2009) showed that irinotecan-induced neutropenia can be explained in part by the UGT1A1*93,ABCC1 IVS $11-48 \mathrm{C}>\mathrm{T}$ and $S L C O 1 B 1^{\star} 1 b 388 \mathrm{~A}>\mathrm{C}$ genetic polymorphisms, but in their study, irinotecan was administered at considerably higher doses $\left(300-350 \mathrm{mg} \mathrm{m}^{-2}\right)$; therefore, it is not surprising that we could not reproduce these associations.

In summary, our results suggest that MTHFR genetic polymorphisms (particularly MTHFR $1298 \mathrm{~A}>\mathrm{C}$ and diplotype) are predictive for grade 3-4 diarrhoea or mucositis when 5-FU is administered as a single agent but not in combination with irinotecan. These findings need to be validated in a larger cohort and the results obtained in the group treated with $5-\mathrm{FU}+$ irinotecan should be interpreted with caution for small sample size and confounding factors. Our study demonstrates that pharmacogenetic-pharmacodynamics studies require certain homogeneity in the selection of patients and therapy and that the presence of concomitant chemotherapeutic agents (such as irinotecan in this study) may confound the results by participating in the global pharmacodynamic events.

\section{ACKNOWLEDGEMENTS}

This study was supported in part by the NIH Pharmacogenetics Research Network (U01 GM63340) and the Siteman Comprehensive Cancer Center, NCI Cancer Center Support Grant P30 CA091842. FT was supported by a grant from 'La Fondation de France'. SR was supported by NIGMS T32GM081057.

\section{REFERENCES}

Aschele C, Pinto C, Cordio S, Rosati G, Tagliagambe A, Artale S, Rosetti P, Lonardi S, Boni L, Cionini L (2009) Preoperative fluorouracil (FU)-based chemoradiation with and without weekly oxaliplatin in locally advanced rectal cancer: Pathologic response analysis of the Studio Terapia Adiuvante Retto (STAR)-01 randomized phase III trial. J Clin Oncol (Meeting Abstracts) 27: CRA4008

Bagley PJ, Selhub J (1998) A common mutation in the methylenetetrahydrofolate reductase gene is associated with an accumulation of formylated tetrahydrofolates in red blood cells. Proc Natl Acad Sci USA 95: 13217-13220

Balboa E, Duran G, Lamas MJ, Gomez-Caamano A, Celeiro-Munoz C, Lopez R, Carracedo A, Barros F (2010) Pharmacogenetic analysis in neoadjuvant chemoradiation for rectal cancer: high incidence of somatic mutations and their relation with response. Pharmacogenomics 11: 747-761

Bertolini F, Chiara S, Bengala C, Antognoni P, Dealis C, Zironi S, Malavasi N, Scolaro T, Depenni R, Jovic G, Sonaglio C, Rossi A, Luppi G, Conte PF (2009) Neoadjuvant treatment with single-agent cetuximab followed by 5-FU, cetuximab, and pelvic radiotherapy: a phase II study in locally advanced rectal cancer. Int J Radiat Oncol Biol Phys 73: $466-472$

Bosset JF, Calais G, Mineur L, Maingon P, Radosevic-Jelic L, Daban A, Bardet E, Beny A, Briffaux A, Collette L (2005) Enhanced tumorocidal effect of chemotherapy with preoperative radiotherapy for rectal cancer: preliminary results - EORTC 22921. J Clin Oncol 23: 5620-5627

Bosset JF, Collette L, Calais G, Mineur L, Maingon P, Radosevic-Jelic L, Daban A, Bardet E, Beny A, Ollier JC (2006) Chemotherapy with preoperative radiotherapy in rectal cancer. $N$ Engl J Med 355: 1114-1123
Braendengen M, Tveit KM, Berglund A, Birkemeyer E, Frykholm G, Pahlman L, Wiig JN, Bystrom P, Bujko K, Glimelius B (2008) Randomized phase III study comparing preoperative radiotherapy with chemoradiotherapy in nonresectable rectal cancer. J Clin Oncol 26: 3687-3694

Capitain O, Boisdron-Celle M, Poirier AL, Abadie-Lacourtoisie S, Morel A, Gamelin E (2008) The influence of fluorouracil outcome parameters on tolerance and efficacy in patients with advanced colorectal cancer. Pharmacogenomics J 8: 256-267

Cassidy J, Twelves C, Van Cutsem E, Hoff P, Bajetta E, Boyer M, Bugat R, Burger U, Garin A, Graeven U, McKendric J, Maroun J, Marshall J, Osterwalder B, Perez-Manga G, Rosso R, Rougier P, Schilsky RL (2002) First-line oral capecitabine therapy in metastatic colorectal cancer: a favorable safety profile compared with intravenous 5-fluorouracil/ leucovorin. Ann Oncol 13: 566-575

Crane CH, Skibber JM, Birnbaum EH, Feig BW, Singh AK, Delclos ME, Lin EH, Fleshman JW, Thames HD, Kodner IJ, Lockett MA, Picus J, Phan T, Chandra A, Janjan NA, Read TE, Myerson RJ (2003a) The addition of continuous infusion 5 -FU to preoperative radiation therapy increases tumor response, leading to increased sphincter preservation in locally advanced rectal cancer. Int J Radiat Oncol Biol Phys 57: 84-89

Crane CH, Skibber JM, Feig BW, Vauthey JN, Thames HD, Curley SA, Rodriguez-Bigas MA, Wolff RA, Ellis LM, Delclos ME, Lin EH, Janjan NA (2003b) Response to preoperative chemoradiation increases the use of sphincter-preserving surgery in patients with locally advanced low rectal carcinoma. Cancer 97: 517-524 
Delaneau O, Coulonges C, Zagury JF (2008) Shape-IT: new rapid and accurate algorithm for haplotype inference. BMC Bioinformatics 9: 540

De Mattia E, Toffoli G (2009) C677T and A1298C MTHFR polymorphisms, a challenge for antifolate and fluoropyrimidine-based therapy personalisation. Eur J Cancer 45: 1333-1351

Dunst J, Reese T, Sutter T, Zuhlke H, Hinke A, Kolling-Schlebusch K, Frings S (2002) Phase I trial evaluating the concurrent combination of radiotherapy and capecitabine in rectal cancer. J Clin Oncol 20: $3983-3991$

Etienne MC, Formento JL, Chazal M, Francoual M, Magne N, Formento P, Bourgeon A, Seitz JF, Delpero JR, Letoublon C, Pezet D, Milano G (2004) Methylenetetrahydrofolate reductase gene polymorphisms and response to fluorouracil-based treatment in advanced colorectal cancer patients. Pharmacogenetics 14: 785-792

Garcia-Aguilar J, Hernandez de Anda E, Sirivongs P, Lee SH, Madoff RD, Rothenberger DA (2003) A pathologic complete response to preoperative chemoradiation is associated with lower local recurrence and improved survival in rectal cancer patients treated by mesorectal excision. Dis Colon Rectum 46: 298-304

Gerard JP, Azria D, Gourgou-Bourgade S, Martel-Laffay I, Hennequin C, Etienne PL, Vendrely V, Francois E, de La Roche G, Bouche O, Mirabel X, Denis B, Mineur L, Berdah JF, Mahe MA, Becouarn Y, Dupuis O, Lledo G, Montoto-Grillot C, Conroy T (2010) Comparison of two neoadjuvant chemoradiotherapy regimens for locally advanced rectal cancer: results of the phase III trial ACCORD 12/0405-Prodige 2. J Clin Oncol 28: 1638-1644

Gerard JP, Conroy T, Bonnetain F, Bouche O, Chapet O, Closon-Dejardin MT, Untereiner M, Leduc B, Francois E, Maurel J, Seitz JF, Buecher B, Mackiewicz R, Ducreux M, Bedenne L (2006) Preoperative radiotherapy with or without concurrent fluorouracil and leucovorin in T3-4 rectal cancers: results of FFCD 9203. J Clin Oncol 24: 4620-4625

Gusella M, Frigo AC, Bolzonella C, Marinelli R, Barile C, Bononi A, Crepaldi G, Menon D, Stievano L, Toso S, Pasini F, Ferrazzi E, Padrini R (2009) Predictors of survival and toxicity in patients on adjuvant therapy with 5-fluorouracil for colorectal cancer. Br J Cancer 100: 1549-1557

Horie N, Aiba H, Oguro K, Hojo H, Takeishi K (1995) Functional analysis and DNA polymorphism of the tandemly repeated sequences in the 5 -terminal regulatory region of the human gene for thymidylate synthase. Cell Struct Funct 20: 191-197

Hoskins JM, Goldberg RM, Qu P, Ibrahim JG, McLeod HL (2007) UGT1A $1 * 28$ genotype and irinotecan-induced neutropenia: dose matters. J Natl Cancer Inst 99: 1290-1295

Innocenti F, Kroetz DL, Schuetz E, Dolan ME, Ramirez J, Relling M, Chen P, Das S, Rosner GL, Ratain MJ (2009) Comprehensive pharmacogenetic analysis of irinotecan neutropenia and pharmacokinetics. J Clin Oncol 27: $2604-2614$

Kaneda S, Takeishi K, Ayusawa D, Shimizu K, Seno T, Altman S (1987) Role in translation of a triple tandemly repeated sequence in the 5 -untranslated region of human thymidylate synthase mRNA. Nucleic Acids Res 15: 1259-1270

Kawakami K, Omura K, Kanehira E, Watanabe Y (1999) Polymorphic tandem repeats in the thymidylate synthase gene is associated with its protein expression in human gastrointestinal cancers. Anticancer Res 19: $3249-3252$

Kawakami K, Salonga D, Park JM, Danenberg KD, Uetake H, Brabender J, Omura K, Watanabe G, Danenberg PV (2001) Different lengths of a polymorphic repeat sequence in the thymidylate synthase gene affect translational efficiency but not its gene expression. Clin Cancer Res 7: 4096-4101

Kawakami K, Watanabe G (2003) Identification and functional analysis of single nucleotide polymorphism in the tandem repeat sequence of thymidylate synthase gene. Cancer Res 63: 6004-6007

Kim TW, Innocenti F (2007) Insights, challenges, and future directions in irinogenetics. Ther Drug Monit 29: 265-270

Largillier R, Etienne-Grimaldi MC, Formento JL, Ciccolini J, Nebbia JF, Ginot A, Francoual M, Renee N, Ferrero JM, Foa C, Namer M, Lacarelle B, Milano G (2006) Pharmacogenetics of capecitabine in advanced breast cancer patients. Clin Cancer Res 12: 5496-5502

Marsh S, Collie-Duguid ES, Li T, Liu X, McLeod HL (1999) Ethnic variation in the thymidylate synthase enhancer region polymorphism among Caucasian and Asian populations. Genomics 58: 310-312

Marsh S, King CR, Garsa AA, McLeod HL (2005) Pyrosequencing of clinically relevant polymorphisms. Methods Mol Biol 311: 97-114

McLeod HL, Sargent DJ, Marsh S, Green EM, King CR, Fuchs CS, Ramanathan RK, Williamson SK, Findlay BP, Thibodeau SN, Grothey A, Morton RF, Goldberg RM (2010) Pharmacogenetic predictors of adverse events and response to chemotherapy in metastatic colorectal cancer: results from North American Gastrointestinal Intergroup Trial N9741. J Clin Oncol 28: 3227-3233

Mohiuddin M, Winter K, Mitchell E, Hanna N, Yuen A, Nichols C, Shane R, Hayostek C, Willett C (2006) Randomized phase II study of neoadjuvant combined-modality chemoradiation for distal rectal cancer: Radiation Therapy Oncology Group Trial 0012. J Clin Oncol 24: 650-655

Myerson RJ, Garofalo MC, El Naqa I, Abrams RA, Apte A, Bosch WR, Das P, Gunderson LL, Hong TS, Kim JJJ, Willett CG, Kachnic LA (2009) Elective clinical target volumes for conformal therapy in anorectal cancer: a Radiation Therapy Oncology Group consensus panel contouring atlas. Int J Radiat Oncol Biol Phys 74: 824-830

Noordhuis P, Holwerda U, Van der Wilt CL, Van Groeningen CJ, Smid K, Meijer S, Pinedo HM, Peters GJ (2004) 5-Fluorouracil incorporation into RNA and DNA in relation to thymidylate synthase inhibition of human colorectal cancers. Ann Oncol 15: 1025-1032

Pullarkat ST, Stoehlmacher J, Ghaderi V, Xiong YP, Ingles SA, Sherrod A, Warren R, Tsao-Wei D, Groshen S, Lenz HJ (2001) Thymidylate synthase gene polymorphism determines response and toxicity of 5-FU chemotherapy. Pharmacogenomics J 1: 65-70

Roh MS, Colangelo LH, O'Connell MJ, Yothers G, Deutsch M, Allegra CJ, Kahlenberg MS, Baez-Diaz L, Ursiny CS, Petrelli NJ, Wolmark N (2009) Preoperative multimodality therapy improves disease-free survival in patients with carcinoma of the rectum: NSABP R-03. J Clin Oncol 27: 5124-5130

Ruzzo A, Graziano F, Loupakis F, Rulli E, Canestrari E, Santini D, Catalano V, Ficarelli R, Maltese P, Bisonni R, Masi G, Schiavon G, Giordani P, Giustini L, Falcone A, Tonini G, Silva R, Mattioli R, Floriani I, Magnani M (2007) Pharmacogenetic profiling in patients with advanced colorectal cancer treated with first-line FOLFOX-4 chemotherapy. J Clin Oncol 25: 1247-1254

Ruzzo A, Graziano F, Loupakis F, Santini D, Catalano V, Bisonni R, Ficarelli R, Fontana A, Andreoni F, Falcone A, Canestrari E, Tonini G, Mari D, Lippe P, Pizzagalli F, Schiavon G, Alessandroni P, Giustini L, Maltese P, Testa E, Menichetti ET, Magnani M (2008) Pharmacogenetic profiling in patients with advanced colorectal cancer treated with first-line FOLFIRI chemotherapy. Pharmacogenomics J 8: 278-288

Sauer R, Becker H, Hohenberger W, Rodel C, Wittekind C, Fietkau R, Martus P, Tschmelitsch J, Hager E, Hess CF, Karstens JH, Liersch T, Schmidberger H, Raab R (2004) Preoperative vs postoperative chemoradiotherapy for rectal cancer. $N$ Engl J Med 351: $1731-1740$

Sharma R, Hoskins JM, Rivory LP, Zucknick M, London R, Liddle C, Clarke SJ (2008) Thymidylate synthase and methylenetetrahydrofolate reductase gene polymorphisms and toxicity to capecitabine in advanced colorectal cancer patients. Clin Cancer Res 14: 817-825

Spindler KL, Nielsen JN, Lindebjerg J, Jakobsen A (2007) Germline polymorphisms may act as predictors of response to preoperative chemoradiation in locally advanced T3 rectal tumors. Dis Colon Rectum 50: 1363-1369

Tan BR, Thomas F, Myerson RJ, Zehnbauer B, Trinkaus K, Malyapa RS, Mutch MG, Abbey EE, Alyasiry A, Fleshman JW, McLeod HL (2011) Thymidylate synthase genotype-directed neoadjuvant chemoradiation for patients with rectal adenocarcinoma. J Clin Oncol 29: 875-883

Terrazzino S, Agostini M, Pucciarelli S, Pasetto LM, Friso ML, Ambrosi A, Lisi V, Leon A, Lise M, Nitti D (2006) A haplotype of the methylenetetrahydrofolate reductase gene predicts poor tumor response in rectal cancer patients receiving preoperative chemoradiation. Pharmacogenet Genomics 16: 817-824

Theodoropoulos G, Wise WE, Padmanabhan A, Kerner BA, Taylor CW, Aguilar PS, Khanduja KS (2002) T-level downstaging and complete pathologic response after preoperative chemoradiation for advanced rectal cancer result in decreased recurrence and improved disease-free survival. Dis Colon Rectum 45: 895-903

Thomas F, Hoskins JM, Dvorak A, Tan BR, McLeod HL (2010) Detection of the G > C SNP and rare mutations in the 28-bp repeat of TYMS using gel-based capillary electrophoresis. Pharmacogenomics 11: 1751-1756

Tsujinaka T, Kido Y, Shiozaki H, Iijima S, Homma T, Sakaue M, Mori T (1992) Schedule-dependent inhibition of thymidylate synthase by 5-fluorouracil in gastric cancer. Cancer 70: 2761-2765

Valentini V, Coco C, Picciocchi A, Morganti AG, Trodella L, Ciabattoni A, Cellini F, Barbaro B, Cogliandolo S, Nuzzo G, Doglietto GB, AmbesiImpiombato F, Cosimelli M (2002) Does downstaging predict improved outcome after preoperative chemoradiation for extraperitoneal locally advanced rectal cancer? A long-term analysis of 165 patients. Int J Radiat Oncol Biol Phys 53: 664-674

Villafranca E, Okruzhnov Y, Dominguez MA, Garcia-Foncillas J, Azinovic I, Martinez E, Illarramendi JJ, Arias F, Martinez Monge R, Salgado E, Angeletti S, Brugarolas A (2001) Polymorphisms of the repeated sequences in the enhancer region of the thymidylate synthase gene 
promoter may predict downstaging after preoperative chemoradiation in rectal cancer. J Clin Oncol 19: 1779-1786

Weisberg I, Tran P, Christensen B, Sibani S, Rozen R (1998) A second genetic polymorphism in methylenetetrahydrofolate reductase (MTHFR) associated with decreased enzyme activity. Mol Genet Metab 64: $169-172$
Willett CG, Duda DG, di Tomaso E, Boucher Y, Ancukiewicz M, Sahani DV, Lahdenranta J, Chung DC, Fischman AJ, Lauwers GY, Shellito P, Czito BG, Wong TZ, Paulson E, Poleski M, Vujaskovic Z, Bentley R, Chen HX, Clark JW, Jain RK (2009) Efficacy, safety, and biomarkers of neoadjuvant bevacizumab, radiation therapy, and fluorouracil in rectal cancer: a multidisciplinary phase II study. J Clin Oncol 27: 3020-3026

This work is published under the standard license to publish agreement. After 12 months the work will become freely available and the license terms will switch to a Creative Commons Attribution-NonCommercial-Share Alike 3.0 Unported License. 